\title{
Trajetória em narrativas: loucuras e a cidade de Belo Horizonte, Brasil
}

\author{
Trajectory in narratives: experiences of mental illness \\ and the city of Belo Horizonte
}

\author{
Amanda Elias Arruda ${ }^{1}$ \\ Ana Lúcia Modesto ${ }^{1}$ \\ Cláudio Santiago Dias Júnior ${ }^{1}$
}

${ }^{1}$ Departamento de Sociologia, Universidade Federal de Minas Gerais. Av. Antônio Carlos 6627, Pampulha. 31270-901 Belo Horizonte MG Brasil. amandaarrudato@ gmail.com

\begin{abstract}
The article seeks to understand the relationships established between mentally ill patients cared for in the open community service network and the city of Belo Horizonte, state capital of Minas Gerais. It is understood that the experience of mental illness is capable of generating narratives that seek to give meaning to suffering and help people to negotiate everyday decisions. The biographical method was used for the construction of narratives of life trajectories of the three participants of the study. The biographical narratives revealed diverse experiences associated with mental illness as well as different meanings attributed to this condition. However, interestingly, these stories have a common pattern, often associated with marginal convivialities with the conventions of order, family and work. There is a break with the striking invisibility in asylums, as open services provide the social movement and manipulation of social codes, creating new territorial delimitations and interpretations. However, the need for empirical studies that address themes such as family relations, housing conditions and income of this population is paramount in order to broaden the right to health discussions for the right to housing, work, the right and to a place in the city.

Key words Mental health, Narrative, Territory
\end{abstract}

Resumo $O$ artigo busca compreender as relações estabelecidas entre portadores de sofrimento mental assistidos em um serviço aberto e comunitário e a cidade de Belo Horizonte (BH), capital do Estado de Minas Gerais. Compreende-se que a experiência da loucura é capaz de gerar narrativas que buscam atribuir sentido ao sofrimento e auxiliam as pessoas a negociar as decisões cotidianas. O método biográfico foi utilizado para a construção das narrativas de trajetórias de vida dos três participantes do estudo. Cada pessoa atribuiu um sentido diferente à experiência da loucura, contudo, percebe-se a existência de trajetóriase sociabilidades marginais às convenções da ordem, da família e do trabalho. Verifica-se uma ruptura com a invisibilidade marcante nos manicômios, uma vez que os serviços abertos proporcionam a circulação social e a manipulação de códigos sociais que entremeiam os deslocamentos, criando novas territorialidades e codificações. Contudo, evidencia-se a necessidade de estudos empíricos que contemplam temáticas como as relações familiares e as condições de moradia e renda dessa população, para, então, ampliar as discussões do direito à saúde para o direito à moradia, ao trabalho, enfim, o direito e o cabimento na cidade.

Palavras-chave Saúde mental, Narrativas, Território 


\section{Introdução}

A loucura encontra-se inserida no contexto dos problemas da cidade, sendo vista, ora no campo da miséria, ora no campo das doenças ${ }^{1}$. Independentemente do ponto de vista de análise, se sob a ótica da miséria ou da doença, essas abordagens evidenciam um distanciamento dos indivíduos portadores de sofrimentos mentais das normas sociais vigentes.

Em Belo Horizonte/MG, diversos registros históricos revelam tipos populares que marcaram a vida da cidade, como, por exemplo, o personagem Jaburu. Segundo relatos, "Jaburu vivia constantemente atormentado pela garotada e pelos grupos de rapazes que se formavam na avenida Afonso Pena. Provocado, manobrava a bengala que nunca abandonava - na mímica agressiva e deflagrava o paiol de virulentos insultos"2. Com o processo de modernização da capital mineira, que acarretou a promoção de um estilo de vida acelerado, o esvaziamento do espaço público e a desumanização das relações sociais, tais personagens, como Jaburu, perderam a visibilidade, isto é, "desapareceram" do espaço urbano.

Atrelado à emergência de uma sociedade moderna, racional, individualista, aos moldes de Simmel $^{3}$, emerge uma sociedade que controla e que busca a ordem, combatendo, dentre várias questões, o desvio à norma social estabelecida. Nessa perspectiva, a loucura, vista como desvio e como doença mental, cabia a resposta científica do manicômio.

Diante destas questões, o presente artigo busca entender as relações estabelecidas entre portadores de sofrimento mental assistidos em um serviço comunitário e aberto e a cidade de Belo Horizonte (BH), capital do Estado de Minas Gerais. Dispositivo urbano de acolhimento à loucura, criado a partir do processo da Reforma Psiquiátrica Brasileira que foi vivenciada intensamente em Minas Gerais e em Belo Horizonte. Este serviço integra a rede de serviços substitutivos ao manicômio de $\mathrm{BH}$ e provoca a cidade e seus moradores a ressignificar e construir novas formas de lidar com a experiência da loucura a partir da ruptura com a lógica da internação e do isolamento social.

O ponto de partida foi a provocação: qual o "cabimento da loucura na cidade"? A partir desta provocação, o objetivo deste trabalho é investigar a relação entre loucura e a cidade de Belo Horizonte, cidade planejada e construída a partir do modelo de modernidade, que priorizou a racionalização do espaço social e a aspiração de um ideal de ordem e de higiene. Dessa forma, qual o cabimento dos desviantes? Essa discussão ganha consistência ao se aproximar da experiência de pessoas portadoras de sofrimento mental que são assistidas em um serviço comunitário e aberto da cidade.

\section{A doença como drama social}

O mundo cotidiano é mais dinâmico e caótico do que revelam as teorias sociais, por isso, este trabalho toma a experiência, e especialmente a experiência da doença, como ponto de partida para conhecer o emaranhado das tramas e dos dramas da vida que marcam o processo saúde/ doença. A partir desse enfoque, este trabalho rompe com os estudos biomédicos e com os trabalhos antropológicos e sociológicos tradicionais. O corpo/objeto da ciência médica é substituído pelo corpo vivido, fonte e condição para a real relação com o mundo dos objetos. No caso dos estudos desenvolvidos pelas Ciências Sociais, há uma ruptura com a ênfase nos aspectos ideais ou simbólicos que faz referência ao corpo/ texto, espelho da cultura, como defende Clifford Geertz, apoiando-se em Max Weber. Ressalta-se a centralidade do corpo vivido, fundamento da inserção humana no mundo da cultura e ponto de partida para a reconstrução contínua desse mundo ${ }^{4}$.

Langdon $^{5}$ afirma que a doença consiste em uma experiência que é capaz de gerar narrativas que buscam atribuir sentido ao sofrimento e auxiliam as pessoas a negociar as decisões cotidianas. No caso da experiência da "doença mental", os significados associados são construções culturais herdadas e utilizadas em situações de aflição $0^{4}$. A experiência da loucura pode ser compreendida como 'problema de cabeça' ou estado de enfraquecimento ou perda do 'juízo'. Estudos antropológicos revelam a existência de signos relacionais, de violência, isolamento, agitação, alterações no discurso, problemas no campo da percepção (delírio e alucinação), ataques e crises, desempenho de papéis sociais, aparência, emoção e comportamento bizarro ${ }^{4}$. Esses signos aproximam-se da ideia de estigma apresentada por Goffman ${ }^{6}$, uma vez que apontam o indicativo de degenerescência: os estigmas do mal, da loucura, da doença, que revelam um indivíduo que poderia ser facilmente acolhido na relação social cotidiana, mas que possui um traço que pode chamar atenção e afastar aqueles que o encontram. A loucura, então, transformada em estigma, faz com que os portadores de sofrimento mental percam a con- 
dição de cidadão, sendo tratados com repulsa, violência simbólica e até mesmo física. Dentro de uma sociedade que enaltece a noção da razão e do racional, o louco aparece como uma ameaça à ordem estabelecida e aos relacionamentos pessoais que fazem a vida da cidade.

\section{As narrativas biográficas: resgatando vidas obscurecidas pela ordem dominante}

O método biográfico pode ser encontrado nas Ciências Sociais de maneira esparsa, ora as histórias de vida apresentam-se como anexos que explicitam dados e ilustrações, ora aparecem com centralidade analítica ${ }^{7}$. Nos estudos nos quais a biografia assume centralidade, observa-se a distinção entre duas formas de se apropriar desse método: as biografias convencionais como objeto e outra, a intenção biográfica para fazer dela uma narrativa etnográfica, assim como $\mathrm{Kofes}^{7} \mathrm{fez}$ na escrita sobre Consuelo Caiado em Uma trajetória em narrativas:

O foco sobre uma singularidade, no caso uma trajetória, revelou várias relações, permitindo que a pesquisa guardasse na intuição biográfica um procedimento etnográfico: orientada pelas perguntas sobre Consuelo Caiado, fui seguindo seus caminhos e o que ouvi e encontrei foi sobre muitas outras coisas. Trata-se agora de escrever sobre esse encontro, entre um itinerário de pesquisa e a trajetória de um sujeito pesquisado ${ }^{7}$.

A metodologia aplicada neste estudo aproxima-se da intenção colocada por Kofes, à medida que a escrita biográfica de pessoas com problemas mentais revelou-se como narrativas das diferentes experiências de loucura e relações com a cidade. A partir da compreensão de que a experiência contém relações, conexões, movimentos de vida, experiência social e reflexão dos próprios sujeitos, as narrativas contemplam uma multiplicidade gráfica de diferentes registros e formas de inscrição como, por exemplo, imagens, as coisas, seus rastros e (re) composições ${ }^{8}$.

\section{Sujeitos de pesquisa}

A escolha dos sujeitos participantes da pesquisa seguiu a amostra intencional. Para a escolha dos sujeitos foram considerados os seguintes critérios: pessoas que possuem histórico de internação psiquiátrica em manicômios, experiência atual de tratamento no Centro de Referência em Saúde Mental da regional Leste de BH - CERSAM Leste (serviço aberto e comunitário de aco- lhimento à loucura substitutivo ao hospital psiquiátrico) e que apresentam atributos diferentes quanto aos seguintes critérios: gênero, moradia e frequência na instituição. A definição desses critérios pretendeu garantir uma diversidade da população atendida nessa instituição. Desse procedimento foram selecionados: (1) um homem que se encontra em situação de rua, frequenta de maneira irregular o CERSAM; (2) uma mulher que mora em uma República (Unidade da Assistência Social da Prefeitura de BH), frequenta diariamente o CERSAM; (3) um homem que mora com a esposa em uma casa, frequenta semanalmente o CERSAM.

\section{Coleta de dados}

Foram realizadas: (1) entrevistas em profundidade com foco em história de vida com as três pessoas; (2) accounts com os participantes da pesquisa e com familiares deles, (3) pesquisa em arquivos como, por exemplo, prontuário de um dos participantes.

Entrevistas com foco na história de vida foram utilizadas para compreender a trajetória de vida dos participantes do estudo ${ }^{9}$. As entrevistas foram gravadas com consentimento dos participantes da pesquisa, em média foram realizadas duas entrevistas com cada participante. Estas não apresentaram roteiro definido, mas uma questão disparadora: Conte um pouco sobre a sua história. Durante a entrevista foram abordados temas como a experiência do adoecimento, as relações sociais e as relações com a cidade.

Relatos ou accounts também foram coletados no trabalho de campo. Segundo Orbuch ${ }^{10}$, esse tipo de estudo tem ganhado relevância entre estudos qualitativos mais interpretativos e centrados no significado que os atores conferem ao mundo social, a partir do aprofundamento de histórias e narrativas da interação social. Foram realizadas conversas informais com familiares dos participantes, como por exemplo, a esposa de um dos participantes e os pais de outro participante.

A análise de prontuários apresentou-se como um recurso viável na construção da narrativa de um dos participantes da pesquisa - Regina Duarte, uma vez que há dificuldade da participante no uso da linguagem e na capacidade de narrar a própria história. Acredita-se que os autos e os prontuários podem ser compreendidos como arquivos de vida do sujeito, nos quais a história de vida é inscrita de forma condensada, como demonstra Scaramello ${ }^{11}$. 


\section{Análise dos dados}

A análise das entrevistas iniciou-se com uma etapa de pré-análise, conforme descrito por Bar$\operatorname{din}^{12}$. As gravações foram escutadas atentamente várias vezes, com o intuito de apreender informações e significados que não aparecem na primeira escuta. Foram realizadas leituras flutuantes e categorização dos dados. Os dados foram ordenados em eixos temáticos elaborados a partir dos objetivos do trabalho. Os eixos elaborados foram: (1) a experiência do adoecimento e (2) trajetos, territorialidades e relações sociais. Esses eixos temáticos foram utilizados para a construção das narrativas de vida dos participantes.

\section{Ética em pesquisa}

Os procedimentos normativos previstos para o desenvolvimento de pesquisa com seres humanos foram cuidadosamente observados. O projeto de pesquisa foi submetido ao Comitê de Ética da Universidade Federal de Minas Gerais, ao Comitê de Ética da Secretaria Municipal de Saúde de Belo Horizonte e também à avaliação da Gerência do Centro de Referência em Saúde Mental da Regional Leste, instituição onde selecionamos e convidamos os participantes. Todas essas instâncias apresentaram parecer favorável ao desenvolvimento da pesquisa. Os participantes foram orientados a respeito dos objetivos do estudo e procedimentos e assinaram o termo de consentimento livre esclarecido.

\section{Resultados: trajetórias em narrativas}

\section{Narrativa de Biduffer}

Biduffer é homem, branco, cinquenta e oito anos, cabelos grisalhos e despenteados, barba branca e olhos verdes. Ele veste-se de maneira singular: sobrepõe peças de roupas, veste camisas, casacos e bermudas por cima de calças. Ele frequenta semanalmente o CERSAM Leste para consultas ambulatoriais e vive, atualmente, na casa da esposa.

Durante a infância e adolescência, ele morou com os pais e os sete irmãos. Apresentou bom desempenho escolar durante o ensino fundamental e o médio. $\mathrm{Na}$ adolescência, ele tem histórico de trabalhos como vendedor de picolé e office-boy em uma instituição bancária da cidade. Entretanto, aos dezoito anos, ao passar no vestibular e cursar três meses de Filosofia na Pontifícia Uni- versidade Católica - PUC, ele identifica signos de ruptura com o curso da vida. Biduffer é enfático em dizer do processo de adoecimento a partir da entrada na faculdade e da abertura às diversas formas de conhecimento:

Quando entrei na PUC, eu pirei, abriu um leque de conhecimento, eu conversei com psicólogo. Os estudos me deixaram louco, não os estudos da grade curricular do curso de Filosofia, mas os estudos da Psicologia, das mulheres, o estudo do ser humano... Eu vi muita mulher bonita, muita gente jovem, o Rock in Rio.... O que me enlouqueceu foi timidez, é fazer tudo e fazer tudo o que falam da gente, tentar resolver o problema antes dos 44 anos, eu sou do tempo de que o mundo ia acabar no ano 2000.... Falar que eu não sou louco é impossível, não tem um só dia que eu não enlouqueço.

$\mathrm{Na}$ trajetória de vida de Biduffer, a rotulação de louco apresenta-se como um fio condutor para a construção da sua história. Nesse sentido, a experiência de vida se confunde com a experiência da loucura. Ao dizer sobre a sua loucura ele relaciona momentos de crise e de alterações na percepção da realidade e da construção do pensamento. É interessante perceber que, após esse momento, existe uma ruptura com o curso da vida e, então, ele inicia um percurso em instituições de saúde, inicialmente, pelos hospitais psiquiátricos: eu fui internado em todos os hospitais psiquiátricos, menos no Psicominas e no Santa Maria, o final da minha carreira foi no Raul.

A inscrição de Biduffer no território da loucura, entretanto, ao longo dos anos e a partir do avento da Reforma Psiquiátrica, subverte uma lógica do aprisionamento ao diagnóstico psiquiátrico e o desempenho exclusivo do papel de doente intimamente relacionado aos itinerários terapêuticos, à medida que lhe permite a inscrição de outros códigos à essa experiência.

O serviço substitutivo só falta apertar um parafuso aqui, outro ali. A diferença é que os serviços substitutivos por questão financeira e por questão de confiança... Eu tenho uma autonomia de voo de 7 em 7 dias. Agora passou para de 15 em 15 dias. Eu acho que o trabalho no serviço substitutivo é um trabalho de confiança, vocês confiam, vocês sabem, vocês veem, vocês têm confiança... Pra sair do surto você tem que ver muita gente bonita, o seu time tem que estar bombando, você tem que ter um motivo para estar fora do CERSAM, porque no hospício você não tinha motivo... a família dava o seu dinheiro e eles gastavam tudo [...] bom motivo é se envolver com a política sem ter rabo preso com ninguém [...] esse é um bom motivo para cair na lucidez! 
A invenção de novos dispositivos de tratamento como o Centro de Convivência, os CERSAM's e a construção da cidadania do portador de sofrimento mental a partir de entidades como, por exemplo, a ASSUSAM- MG (Associação dos Usuários de Saúde Mental de Minas Gerais, que consiste em uma entidade criada em 1994, com intuito de proteger os direitos das pessoas portadoras de sofrimento mental e seus familiares, assim como divulgar e defender os princípios da Reforma Psiquiátrica) permitiu novas territorialidades. Assim, ele apresenta-se como um louco -esposo, um louco-presidente e um louco-ator.

No âmbito privado, ele diz das relações afetivas com a esposa que se apresentam de forma intensa, por vezes, conflituosas e das atividades com o corpo, a alimentação e tarefas domésticas. No que diz respeito às relações com os irmãos e a mãe, ele ressalta meus pais e meus irmãos não são minha família, eles são meus parentes, minha família é minha esposa, o que revela uma frouxidão dos laços primários. No âmbito público, ele toma a cena a partir da inscrição na militância política, por meio da participação na ASSUSAM-MG e, atualmente, como presidente, participa de fóruns e de discussões em territórios como a Câmara dos Vereadores, as Universidades e as Conferências de Saúde. Ainda na cena pública, ele apresenta-se como um ator de teatro do Grupo Sapos e Afogados (grupo de teatro que, há cerca de 11 anos, surgiu nos dispositivos da Reforma Psiquiátrica de Belo Horizonte, especificamente no Centro de Convivência César Campos, como oficina de teatro para os usuários da rede de saúde mental. Atualmente é um grupo independente e desvinculado da rede) e ocupa lugares na cidade como os Centros de Convivências, o Galpão Cine Horto (centro cultural do Grupo Galpão, importante companhia de teatro no cenário da cidade de Belo Horizonte e no cenário nacional) e, especialmente, como artista de rua a partir da inscrição em ruas e praças da cidade, como a Praça Floriano Peixoto e a Praça da Liberdade. Como artista, ele já atuou em diferentes espetáculos, dentre eles "Papo de Anjo", "Cinema da Visibilidade Íntima”, "Caixa Preta", "Isso não é um sorvete", entre outros. Contudo, acerca dessa atividade, ele ressalta:

Eu sou ator de carteirinha, na minha carteira profissional está lá profissão: artista. E eu já era louco há muito tempo, pois desde dezoito anos eu enlouqueci [...]. Aí eu fiz um teste, vamos fazer a Caixa Preta, foi Caixa Preta o primeiro trabalho?! Eu ganho um cachezinho, ajuda. Tem um retorno financeiro, mas não é um retorno financeiro que eu esperava...
A narrativa de Biduffer revela signos do estigma (a fragilidade dos laços familiares e a exclusão do mercado formal de trabalho). Contudo, há um movimento de desconstrução do personagem do louco enquanto um indivíduo perigoso, e a inscrição na cidade de Belo Horizonte por meio da arte e da política, adotando a imagem do maluco beleza.

\section{Narrativa de Regina Duarte}

Regina é uma mulher de trinta e nove anos, branca, sobrepeso, baixa estatura, cabelo raspado. Ela apresenta pele bastante queimada de sol, várias cicatrizes nos braços, marcas e machucados no rosto. Em alguns momentos ela apresenta-se enfeitada com colares, brincos, pulseiras e vestidos estampados, em outros momentos apresenta-se descuidada, veste retalhos de roupa e ora apresenta-se nua. Ela frequenta diariamente o CERSAM e atualmente, mora na República Maria Maria (serviço de acolhimento e abrigamento da Assistência Social).

A narrativa de Regina revela a situação de tensão vivenciada no contexto familiar, devido a presença de dificuldades econômicas e de fugas constantes dela da casa para a rua. Regina é nascida em Sabará e, aos dezessete anos, sai de casa e se lança às ruas de $\mathrm{BH}$. $\mathrm{O}$ movimento de ir para rua é interpretado pelos irmãos como perda do juízo, enquanto os pais avaliam como problemas de ordem espiritual.

Os comportamentos desviantes tomam a cena pública, quando ela ocupa espaços públicos de Belo Horizonte e envolve-se em situações, como, por exemplo, arremessar pedras nos bancos da Praça Sete (centro nervoso da cidade, cruzamento entre importantes avenidas de $\mathrm{BH}$ ) ou ser encontrada nua e deitada na avenida Afonso Pena, durante a Feira Hippie (feira de artesanato tradicional da cidade). A partir do tensionamento com a ordem pública, ela inicia percurso pelos serviços de saúde encaminhada ora pela Polícia Militar, ora pelo Serviço de Atendimento Móvel de Urgência - SAMU. Os comportamentos desviantes e bizarros adquirem significado de adoecimento para Regina quando ela inicia itinerário por instituições psiquiátricas. Uma vez que, inscrita nesse circuito, ela passa a dizer: eu faço tratamento pra nervosismo e desmaios.

A inserção de Regina no circuito da Saúde Mental acarreta uma ruptura com os laços primários, uma vez que a internação nas instituições psiquiátricas, como Instituto Raul Soares - IRS e, posteriormente, a vinculação ao CERSAM Leste, 
aumentaram a distância entre Regina e a família. Dessa forma, o espaço privado é esvaziado de sentido e o espaço público aparece como palco para a experiência de vida de Regina. Atualmente, o cotidiano de Regina consiste em passar os dias no CERSAM e as noites na República Maria Maria. Entretanto, há desvios de rota, é comum saídas para o centro da cidade, a Praça Sete e a Feira Hippie, aos domingos. Apesar desses movimentos é comum que, após essas saídas, ela seja novamente capturada pelo circuito da Saúde Mental, uma vez que, quando está na rua, o SAMU é acionado e, então, ela é encaminhada ao Serviço de Urgência Psiquiátrica Noturna - SUP, quando noite e ao CERSAM, quando dia.

O papel de portadora de sofrimento mental ganha visibilidade na história de Regina, uma vez que, a partir dessa identidade, ela se inscreve na cidade de Belo Horizonte. Do anonimato da multidão na rua, ela ganha corpo e nome. Suas atuações foram estampadas na matéria do Jornal Estado de Minas, de 07 de janeiro de 2007: “'Atriz’ estendida no asfalto: tensão do dia a dia dos operadores das câmeras, normalmente é quebrada pelas performances de Regina Duarte de $\mathrm{BH}$, que finge estar ferida para chamar atenção". Entretanto, essa nomeação tem aprisionado a mesma em espaços sociais delimitados e excluído de outros cenários da vida e trocas sociais.

A narrativa de Regina Duarte revela o tipo "nervoso" de Duarte ${ }^{13}$, uma vez que ela apresenta sintomatologia física como aflição, desmaio e perda de consciência, assim como, sintomas morais, por exemplo, ela apresenta-se abobada, desorientada, agitada e furiosa. Entretanto, ao contrário dos "nervosos" que no estudo de Duarte eram acolhidos pela família e cuidados no espaço da comunidade, a inscrição de "nervosa", em uma metrópole como $\mathrm{BH}$, tem provocado uma relação paradoxal: se por um lado ele identifica e dá um nome à Regina no meio da multidão, por outro lado, essa rotulação a exclui, uma vez que evoca os estigmas da loucura. A categoria nervosa de Duarte comporta comportamentos excêntricos que são significados na comunidade como resultado de problemas dos nervos. A excentricidade dos nervosos, por sua vez, tem lugar à ordem comunitária. A experiência de Regina, contudo, é significada nos grandes centros urbanos a partir do discurso psiquiátrico que impõe à experiência da loucura signos do mal, do anormal. Então, o nervoso tem condição de pessoa social desprezada, é temido e tratado como um anormal perigoso à ordem pública.

\section{Narrativa de James}

James é um homem, negro, alto, cinquenta e dois anos. Ele sempre é cordial e bem-humorado. Às vezes apresenta-se no CERSAM Leste com os olhos vermelhos e hálito etílico. Normalmente está com uma mochila nas costas e um boné. Ele chega fica poucos minutos na instituição, toma remédio, toma o café da manhã e, em seguida, pede liberação para ir embora.

Ele é nascido em São Paulo (SP), não conheceu os pais biológicos, foi criado pela madrinha. Após adoecimento da madrinha e mudança dela para a cidade de Bebedouro, no interior de SP, ele afirma o aparecimento dos problemas mentais:

Adoeci, não sei... Acabou a memória, acabou a lucidez, eu ficava andando pela rua, não reconhecia ninguém.... Eu tava numa fase muito difícil da minha vida. Eu fiquei sozinho em casa com um irmão mais complicado do que eu.... Aí eu não suportei. Os parentes naquela época não dava apoio...

$\mathrm{Na}$ história de James, à experiência da loucura é possível atribuir o fenômeno da errância não precisa de voltar pra casa, não, o mundo é grande. Aí que eu comecei a viver a vida. Cair no trecho é a expressão que James utiliza para dizer da sua errância, sempre rodando trecho, Mato Grosso, Bahia, Curitiba, Paraguai, Argentina... Eu sei que o que Deus fez tá feito. Os constantes deslocamentos podem ser compreendidos como narrativa para dar sentido à situação de aflição. James revela a existência de laços primários inconstantes eu fiquei sozinho em casa... Os parentes não davam apoio, você sabe como é família, quando tá tudo bem, tá tudo bem, quando atrapalha, atrapalha tudo!

James, então, inicia trajetória nas ruas. Para entender a trajetória de vida de James, propõese a leitura das classificações referentes à heterogeneidade do universo da população de rua. A categoria trecheiro nos apresenta pertinente. Conforme Consoante Mendes ${ }^{14}$, são chamados trecheiros aqueles que fazem da estrada - do trecho - seu território existencial. Contudo, é comum a construção do território existencial dos andarilhos pela apropriação dos lugares em que se encontram e dos recursos a que têm acesso e não por uma demarcação espacial ${ }^{14}$.

$\mathrm{Na}$ narrativa de James é importante reconhecer no que trecho-corpo-casa-instituição se encontram em um mesmo território: a rua. $\mathrm{Na}$ rua, os andarilhos, quando levados a se fixar, acabam por construir moradias e estabelecer fronteiras que marcam um interior e um exterior; os trecheiros se institucionalizam rapidamente nas 
cidades; contudo, o corpo permanece como território importante.

James diz de uma relação acolhedora com Belo Horizonte e é capaz de identificar lugares na cidade: o Abrigo, a Pastoral de Rua, o CERSAM. Ele acessa tanto dispositivos da Saúde quanto da cultura, mas levanta questões com relação ao direito ao trabalho Tô sem profissão na minha carteira. Minha carteira, acho que nunca foi assinada, só uma vez em SP, como ajudante de tipógrafo, a vida assim é, a gente tem que trabalhar pra viver. $\mathrm{E}$ questiona o direito à moradia:

Aqui eu tô sentido com pé no chão. O tratamento aqui é bom, mas esse negócio de voltar pra casa, tá difícil.... Eu tenho esperança ainda, não sei se vou aguentar esse movimento da sociedade, alugar um lugar, pagar conta. Eu só, sozinho eu não aguento, não, se eu tivesse uma companheira...

Ao contrário da noção de identidade individualizada, definida enquanto unidades totais, optou-se pela ideia de territorialidade, uma vez que, é possível reconhecer uma rede de sinais que se encontram fragmentados por diversas segmentariedades, assim como descreve Perlongher $^{15}$. Sendo assim, ele se inscreve na cidade por meio de deslocamentos e movimentos e pelo nome "andarilho", e o seu circuito revela territórios existenciais, como o corpo e a rua. Se na juventude, aos vinte e dois anos, ele explica o adoecimento com um estado de perda de memória e da lucidez e descreve sua passagem por hospitais psiquiátricos, atualmente, ele questiona a existência de problemas mentais e faz referências às dificuldades cotidianas de moradia e de trabalho.

\section{Discussão: trajetórias de vida, sociabilidades e a cidade}

As trajetórias transformadas em narrativas revelam a existência de pontos comuns às histórias de vida, como, por exemplo, a fragilidade dos laços familiares, a tensão entre a casa e a rua e a exclusão do trabalho formal. Esses atributos dizem da existência de trajetórias marginais, uma vez que, as pessoas apresentam dificuldade ou impossibilidade de articular uma identidade, já que a aversão ou o relativo estranhamento a respeito das convenções da ordem, da família e do trabalho enfraquecem ou tornam-se frouxas, ou pelo menos, inconstantes ${ }^{15}$. Nessa lógica, observamse sociabilidades marginais que apontam para a existência de dois fenômenos: a desterritorialização e a reterritorialização. As experiências da loucura, tal como apresentadas pelas narrativas biográficas apresentadas, mostram esse fenômeno a partir da desterritorialização com relação aos códigos familiares, "normais" e do trabalho e a reterritorialização por meio da apreensão de novos códigos internos ao grupo, que indicam ou traduzem variações comportamentais, gestuais e corporais e a reelaboração de laços de sociabilidade.

As trajetórias de vida dos três participantes do estudo revelam relações fracas, frouxas ou inconstantes com familiares. $\mathrm{Na}$ narrativa de Biduffer, é importante enfatizar o esforço que ele faz para distinguir família e parente, o que revela uma fragilidade dos laços primários e o exercício de construção de novos laços afetivos. A dificuldade do convívio doméstico é evidenciada quando ele, enquanto presidente, que ele explica como um quarto em qualquer casa que poderia abrigar diferentes pessoas, quando elas estivessem passando por dificuldades de convivência e conflitos familiares, você dorme lá, depois no outro dia, volta pra casa. Na história da Regina Duarte, é possível verificar conflitos constantes, um enfraquecimento dos laços e, consequentemente, o abandono da família. Na história de James, a frouxidão e a inconstância dos laços primários de sociabilidade também se faz presente e a saída para os impasses está no deslocamento do ambiente doméstico para as ruas, assim como pôde ser observado na narrativa de Regina.

O enfraquecimento dos laços familiares de portadores de sofrimento mental traz consequências às relações estabelecidas entre eles e a casa/a rua e, consequentemente, o espaço privado/ espaço público. Segundo DaMatta ${ }^{16}$, no espaço doméstico e no espaço público, o brasileiro adota ações diferenciadas e éticas que diferem em cada um desses espaços: o espaço da casa revela-se a partir de uma ética conservadora, enquanto a rua como locus de uma ética liberal. As trajetórias de vida dos nossos participantes apontam que, se não há cabimento para comportamentos bizarros, inadequados na ética conservadora da casa, a rua apresenta-se como um lugar possível para existir, como aponta Lobosque ${ }^{17}$ : "A rua talvez não seja nunca o traçado ordenado e puro da circulação pública; será sempre, talvez, o espaço e o lugar possíveis para a errância, o extravio, a extravagância dos sujeitos, para a absurda falta de cabimento de cada um de nós".

Contudo, segundo DaMatta ${ }^{16}$, o universo cultural brasileiro é avesso à igualdade, o que se reflete na desvalorização da ideia de cidadania e na valorização da deslealdade nas relações competitivas, o que torna a rua um lugar especialmen- 
te perigoso. Daí a exigência do aprendizado de táticas e estratégias de sobrevivências para viver na ou da rua. As narrativas ilustram situações de violência, como, por exemplo, abusos sexuais sofridos por Regina e o movimento constante para tirar sustento da rua, como descrito na trajetória de vida de James. A violência e os abusos sexuais sofridos pela Regina demonstram a ausência da consciência social do indivíduo na esfera pública no Brasil. O doente é visto, muitas vezes, como ameaça à ordem. Entretanto, observa-se a condição de vulnerabilidade presente nas trajetórias de vida. Há situações nas quais eles apresentam-se indefesos e cercados por pessoas que são classificadas como normais, mas que se comportam de forma bárbara. Em lugar da ordem, o que vigora é lei do mais forte, como nas sociedades bárbaras. Observa-se uma questão política grave: a ordem social está fragilizada, há uma loucura pública ou cívica mais perigosa que as experiências individuais de sofrimento. Essa loucura pública ameaça não só os doentes, como também os sãos e constitui-se como um mal que não está em tratamento. Compreende-se a existência de um paradoxo: não é o louco que causa problemas, ele é vítima potencial de uma anomia pública.

A desterritorialização com relação aos códigos familiares tensiona a dimensão do público e do privado, à medida que, se observa uma mistura entre o espaço da rua e da casa, o que, segundo DaMatta ${ }^{16}$, acarreta uma forma grave de confusão e conflitos. Nas trajetórias de vida analisadas é possível perceber atributos do universo da rua que se chocam com a ética doméstica, como, por exemplo, as saídas de Regina de casa e a mendicância que não são toleradas por uma família religiosa, e o uso de drogas de James. A dimensão do público e do privado, dessa forma, é tensionada. Nessa lógica, as nossas narrativas biográficas rompem com a ideia de uma cidade racionalizada por meio da existência de procedimentos urbanísticos nas metrópoles que tendem: a isolar segmentos sociais; normatizar espaços de moradia e de passagem; a manter os corpos isolados e anestesiados e a provocar um esvaziamento da rua, enquanto um lugar de encontro, uma vez que, a superposição de lugares cria atores e cenários limiares e marginais, não definidos por parâmetros sociais convencionais ${ }^{18}$.

Nas três narrativas, é interessante notar o esvaziamento de sentido atribuído à esfera doméstica, ao cotidiano privado e a valorização do uso do espaço urbano. Na história de Biduffer, as ruas e as praças são cenários, palcos para sua arte de rua. Na história da Regina, a rua, a Praça Sete e a Feira Hippie apresentam colorido afetivo, uma vez que, quando questionada sobre o porquê de ir até esses locais, ela diz "lá eu tenho amigos", o que lhes configuram sentidos de lugar. Na história de James, quando a casa é no território da rua, não são apenas as relações sociais privadas que invadem o espaço público, ou que são invadidas por este. As narrativas apontam que a relação da loucura com a rua rompe com a concepção dos espaços públicos, das praças e das calçadas como espaços de passagem, esvaziados da produção de sociabilidade.

A desterritorialização também se encontra presente no campo do trabalho e dos estudos. $\mathrm{Na}$ história de Biduffer, observamos uma ruptura com o trabalho formal e o abandono da Faculdade de Filosofia. A inserção no campo do trabalho dá-se pela nomeação de artista, contudo, ele próprio problematiza o retorno financeiro de tal atividade, o que revela, apesar da importância do processo criativo, que há precariedade financeira. A história de Regina é marcante, a ideia de que ela não foi cunhada para o trabalho - "ela nunca aprendeu nada". James, por sua vez, apesar do aprendizado de ofícios, como, por exemplo, de tipógrafo, não possui um corpo disciplinado para o trabalho formal, que exige rotinas e padrões.

Ao fenômeno de desterritorialização encontra-se a reterritorialização. Os novos grupos, ou "códigos-territórios" são distintos nas narrativas biográficas. Biduffer se reterritorializa no universo da loucura, da arte e da militância política. A nomeação de louco o inscreve nos signos da loucura, das artes cênicas, enquanto ator de teatro do grupo "Sapos e Afogados" e na presidência da ASUSSAM-MG. Na história de Regina Duarte, é marcante o processo de desterritorialização e a tentativa de reterritorializar-se a partir da imersão no universo da loucura e do signo do nervoso. James, por sua vez, reterritorializa-se a partir do universo do andarilho, que faz do corpo seu território existencial e nos trabalhos informais existentes em cada trecho.

\section{Considerações finais}

A partir da construção das narrativas, percebe-se que cada pessoa atribui um significado diferenciado à experiência da loucura, pode-se apreender por meio da imagem do maluco beleza, do nervoso e do andarilho. Entretanto, as histórias de vida apontam a existência de trajetórias marginais, uma vez que, é possível notar o enfraquecimento dos laços familiares e a exclusão 
de processos de produção da vida, o trabalho. A rua e o espaço público tomam a cena nas trajetórias de vida. Observam-se diferentes ocupações e usos desses espaços que extrapolam a concepção de lugar de passagem e de deslocamento. $\mathrm{O}$ fenômeno reterritorialização faz-se presente a cada trajetória. Novos códigos e territorialidades coexistem: a arte, a militância política; a errância, a mendicância; o uso prejudicial de drogas e realização de trabalhos informais. É importante ressaltar que o fenômeno da reterritorialização é particular em cada caso e depende da possibilidade de cada sujeito fazer novas leituras de contexto de vida.

Apesar da Reforma Psiquiátrica, ainda pode ser observada a manutenção do estigma da lou- cura, porém, os loucos diante do outro que o estigmatiza não se mantém passivos ou invisíveis, asilados nos muros dos hospitais psiquiátricos. A constituição de um serviço territorial, comunitário e aberto provoca os mecanismos de circulação social. A forma de resistir é se fazer sair da invisibilidade, tomar a cena, manipular códigos sociais que entremeiam os deslocamentos, criando novas territoralidades e codificações. Entretanto, evidencia-se a necessidade de estudos empíricos que contemplam temáticas como: as relações familiares, as condições de moradia e renda dessa população, para, então, ampliar as discussões do direito à saúde para o direito à moradia, ao trabalho, enfim, o direito e o cabimento na cidade.

\section{Colaboradores}

AE Arruda, AL Modesto e CS Dias Júnior trabalharam na concepção, na coleta de dados, na pesquisa, na metodologia e na redação final. 


\section{Referências}

1. Foucault M. História da Loucura na Idade Clássica. São Paulo: Perspectiva; 1978.

2. Amorim O. Os tipos populares desapareceram quando os arranha-céus começaram. Diário de Minas. Belo Horizonte, 14 de fevereiro de 1958. [acessado 2015 Nov 10]. Disponível em: http://www.jangadabrasil.com.br/ revista/marco122/pa12203.asp

3. Simmel G. A metrópole e a vida mental. In: Velho OG. O fenômeno urbano. Rio de Janeiro: Zahar; 1973.

4. Rabelo MCM, Alves PCB, Souza IMA. Experiência de doença e narrativa [online]. Rio de Janeiro: Editora Fiocruz; 1999. [acessado 2015 Nov 10]. Disponível em: http://static.scielo.org/scielobooks/pz254/pdf/rabelo-9788575412664.pdf

5. Langdon EJ. Os diálogos da antropologia com a saúde: contribuições para as políticas públicas. Cien Saude Colet 2014; 19(4):1019-1029.

6. Goffman E. Estigma: notas sobre a manipulação da identidade deteriorada. Rio de Janeiro: Zahar; 1980.

7. Kofes S. Uma trajetória em narrativas. Campinas: Mercado de letras; 2001.

8. Kofes S, Manica D. Apresentação. In: Kofes S, Manica $\mathrm{D}$, organizadores. Vidas e grafias: narrativas antropológicas, entre biografia e etnografia. Rio de Janeiro: Lamparina, Faperj; 2015.

9. Alberti V. Manual de história oral. $2^{\mathrm{a}}$ ed. Rio de Janeiro: FGV; 2004.

10. Orbuch's T. People's Accounts Count. Annual Review of Sociology 1997.

11. Scaramello ML. Biografias judiciárias: analisando laudos psiquiátricos de autos de processos penais. In: Kofes S, Manica D, organizadores. Vidas e grafias: narrativas antropológicas, entre biografia e etnografia. Rio de Janeiro: Lamparina, Faperj; 2015.

12. Bardin L. Análise de conteúdo. Lisboa: Edições 70; 1979.

13. Duarte LFD. Da vida nervosa nas classes trabalhadoras urbanas. Rio de Janeiro: CNPq, Jorge Zahar; 1986.

14. Mendes MVB. Os moradores de rua e suas trajetórias [dissertação]. Belo Horizonte: Universidade Federal de Minas Gerais; 2007.

15. Perlongher N. Territórios marginais. Campinas: IFCH, Unicamp; 1991. n. 27

16. Damatta R. A casa e a rua: espaço, cidadania, mulher e morte no Brasil. Rio de Janeiro: Rocco; 2000.

17. Lobosque AM. Um desafio à formação: nem teoria, nem o medo da invenção. Cadernos de Saúde Mental. Lobosque AM. Encontro Nacional de Saúde Mental, Belo Horizonte, 2006. Belo Horizonte. ESP-MG, 2007, p. 33-44.

18. Frangela SM. Corpos urbanos errantes: uma etnografia da corporalidade de moradores de rua em São Paulo. São Paulo: Anablume, Fapesp; 2009.

Artigo apresentado em 18/04/2016

Aprovado em 22/06/2016

Versão final apresentada em 24/06/2016 